\title{
COMPARATIVE GENOME-WIDE DNA METHYLATION ANALYSIS IN MYOCARDIAL TISSUE FROM DONORS WITH AND WITHOUT DOWN SYNDROME
}

Romina B. Cejas ${ }^{a, d}$, Jie Wang ${ }^{b, d}$, Rachael Hageman-Blair ${ }^{c}$, Song Liu ${ }^{b}$ and Javier G. Blanco ${ }^{a, e}$ Authors' affiliation:

a Department of Pharmaceutical sciences, School of Pharmacy and Pharmaceutical Sciences, State University of New York at Buffalo, Buffalo, New York, United States of America

${ }^{b}$ Department of Biostatistics and Bioinformatics, Roswell Park Comprehensive Cancer Center, Buffalo, New York, United States of America

${ }^{c}$ Department of Biostatistics, School of Public Health and Health Professions, State University of New York at Buffalo, Buffalo, New York, United States of America

${ }^{\mathrm{d}}$ Both authors contributed equally to this work.

e Corresponding author. jgblanco@buffalo.edu. Department of Pharmaceutical Sciences, School of Pharmacy and Pharmaceutical Sciences, University at Buffalo, The State University of New York, 470 Pharmacy Building, Buffalo, NY 14214 - 8033, United States of America 


\section{Abstract}

Down syndrome (DS, trisomy 21) is the most common major chromosomal aneuploidy compatible with life. The additional whole or partial copy of chromosome 21 results in genomewide imbalances that drive the complex pathobiology of DS. Differential DNA methylation in the context of trisomy 21 may contribute to the variable architecture of the DS phenotype. The goal of this study was to examine the genomic DNA methylation landscape in myocardial tissue from non-fetal individuals with DS. More than 480,000 unique CpG sites were interrogated in myocardial DNA samples from individuals with $(n=12)$ and without DS $(n=12)$ using DNA methylation arrays. A total of 93 highly differentially methylated $\mathrm{CpG}$ sites and 16 differentially methylated regions were identified in myocardial DNA from subjects with DS. There were 18 differentially methylated CpG sites in chromosome 21, including 5 highly differentially methylated sites. A CpG site in the RUNX1 locus was differentially methylated in DS myocardium, and linear regression suggests that donors' age, gender, DS status, and RUNX1 methylation may contribute up to $\sim 51 \%$ of the variability in $R U N X 1$ mRNA expression. In DS myocardium, only $58 \%$ of the genes overlapping with differentially methylated regions codify for proteins with known functions and $24 \%$ are non-coding RNAs. This study provides an initial snapshot on the extent of genomewide differential methylation in myocardial tissue from persons with DS. 


\section{Keywords}

Epigenetics, Myocardium, Trisomy 21, Cardiac methylation, Heart

\section{Abbreviations}

DS, Down syndrome; non-DS, non-Down syndrome; DNA, deoxyribonucleic acid; $R U N X 1$, runt-related transcription factor 1; RNA, ribonucleic acid; mRNA, messenger RNA; DMR, differentially methylated region; SNP, single nucleotide polymorphism; FDR, false discovery rate; $A C T B$, actin beta; PCR, polymerase chain reaction; RT-qPCR, quantitative reverse transcription polymerase chain reaction; DSCR, Down syndrome critical region; GO, gene ontology; RRBS, reduced representation bisulfite sequencing. 


\section{Introduction}

In humans, Down syndrome (DS, trisomy 21) is the most common major chromosomal abnormality compatible with life, with an approximate incidence of 1 in 700 to 1 in 900 live births (1). DS is caused by the presence of a full or partial extra copy of chromosome 21 . Individuals with DS exhibit a range of phenotypic characteristics and distinctive physical features. Persons with DS are at increased risk for the development of various comorbidities through the lifespan. In general, the incidence of congenital heart disease, thyroid gland dysfunctions, eye and hearing disorders, pediatric leukemia, and testicular cancer is higher in persons with DS in comparison to individuals without DS (2). For example, the incidence of congenital heart disease in the DS setting is 50 times higher than in the "general population", and the prevalence of congenital heart defects in individuals with DS ranges from $43 \%$ to $58 \%(3,4)$.

Variable DNA methylation levels in specific regions across the genome influences the control of gene expression in different cell types and tissues. In general, relative increases in the levels of methylation in distinct CpG dinucleotides located in gene promoter regions or other regulatory regions may result in transcriptional repression (5). Differential DNA methylation in the context of trisomy 21 may contribute to the complex architecture of the DS phenotype. In this regard, the presence of differentially methylated loci has been examined in some tissues from subjects with DS. For example, Serra-Juhé et al. interrogated approximately 28,000 CpG sites in fetal heart DNA samples from donors with DS and congenital heart defects (CHD) and in samples from donors with DS and without CHD. The authors found that regions in the GATA4 gene were hypermethylated in cardiac DNA from fetuses with DS with or without CHD, as well as in fetuses with isolated heart malformations (6).

There is a paucity of reports describing the genomic DNA methylation landscape in myocardial tissue from non-fetal individuals with DS. The goal of this pilot study was to examine genome-wide DNA methylation profiles in myocardial DNA samples from donors with and without 
bioRxiv preprint doi: https://doi.org/10.1101/2020.07.15.203075; this version posted July 15, 2020. The copyright holder for this preprint (which

was not certified by peer review) is the author/funder, who has granted bioRxiv a license to display the preprint in perpetuity. It is made available under aCC-BY-ND 4.0 International license.

DS. Myocardial DNA samples were examined to interrogate $>480,000$ individual CpG sites using the Illumina HumanMethylation450 BeadChip platform. Next, bioinformatic analysis was performed in order to identify differentially methylated loci in myocardial methylomes. This study contributes new data to continue to define the extent of epigenetic variability in the context of DS. 


\section{Materials and Methods}

\subsection{Human Tissue Specimens}

The Institutional Review Board of the State University of New York at Buffalo (UB-IRB) approved this research. UB-IRB determined that this research is not research with human subjects. This research meets exempt criteria, 45 CRF 46,101(b)(4). Human myocardial tissue samples were provided by the National Disease Research Interchange (NDRI), the Cooperative Human Tissue Network (CHTN), and the National Institute of Child Health and Human Development Brain and Tissue Bank (NICHD-BTB). As per Federal and State regulations, tissue banks require every procurement site to obtain informed consent in compliance with all regulations governing that process in writing from any donor of human tissue (or the next of kin thereof) for the use of tissue for research. Each signed consent form is kept on file at the tissue acquisition site and information is never released to any third party. Tissue banks assign computer generated codes to each donor and do not maintain any information that could be used to identify the donor. Tissue banks provide anonymous samples coded with unique sample identification numbers. Procurement protocols for this project were reviewed and approved by NDRI, CHTN, and NICHD-BTB. Myocardium samples from left ventricles weighing 0.8 - $100 \mathrm{~g}$ were recovered $<20$ hours postmortem and snap frozen in liquid nitrogen. Upon arrival samples were stored in liquid nitrogen until further processing. Donor demographics are shown in Supplementary Table 1.

\subsection{Nucleic Acid Extraction \& Illumina Methylation Assay}

Genomic DNA from myocardium was extracted and purified with AutoGen QuickGene DNA Tissue Kit S and an AutoGen QuickGene-810 Nucleic Acid Isolation System (AutoGen Inc). DNA concentrations were measured using a Quant-iT PicoGreen dsDNA Assay Kit (Life Technologies, Thermo Fisher Scientific) following the manufacturer's instructions. The quality of DNA samples (260 nm/230 nm absorbance ratios) was also examined using a NanoDrop 1000 
Spectrophotometer (Thermo Scientific). DS status (i.e., trisomy 21) had been previously confirmed by array comparative hybridization as described (7). Genome-wide methylation analysis was performed by interrogating 482,421 unique CpG sites using the Illumina HumanMethylation450 BeadChip platform (Illumina) at the Genomics Shared Resource, Roswell Park Comprehensive Cancer Center, Buffalo, NY (8). BeadChips were scanned using an iScan Reader (Illumina), and analysis was conducted using GenomeStudio v2011.1 (Illumina).

\subsection{Genome-Wide Methylation Analysis}

Genome-wide methylation data, in the form of intensity data (IDAT) files, were compiled in GenomeStudio v2011.1 and processed using the R package minfi following the recommended workflow $(9,10)$. A detection $p$-value was generated for every CpG site in each sample to compare the total signal for each probe to the background signal. Samples with high mean detection $\mathrm{p}$ values were defined as poor quality samples and were excluded from downstream analysis. None of the 24 DNA samples were identified as poor-quality sample. Data normalization was performed using the stratified quantile normalization method in the minfi package. Then, probes with unreliable signals were filtered out before differential methylation analysis. Probes with high detection $p$-value $(p \geq 0.01)$ in any sample were excluded. Probes located on sex chromosomes or those known to have common single nucleotide polymorphisms (SNPs) at the CpG site were filtered out and were not included in subsequent analyses. Probes showing to be cross-reactive due to multiple mapping in the genome were also filtered out (11). All remaining probes were used in the downstream analysis.

Beta values ( $\beta$ value) were used to define methylation, ranging from $0-1$, for individual probes or genomic regions. Differential methylation analysis was conducted on individual CpG sites, as well as in defined genomic regions (i.e., loci). Individual CpG sites and genomic regions were identified as statistically significantly differentially methylated between DS and non-DS samples following correction for multiple testing using the Benjamini-Hochberg false discovery 
rate (FDR), with a 5\% FDR cut off. Highly differentially methylated CpG sites and regions were identified as those with significant $p$-values and an absolute methylation difference greater than 0.100 (i.e., $\beta$ difference > 10.0\%). Analysis of differentially methylated regions (DMR) was performed with the DMRcate package, which identifies and ranks the DMR based on a kernel smoothing of the differentially methylated CpG sites (12). Genomic location of individual CpG sites, genic regions, and corresponding gene names were obtained from the UCSC Genome Browser (hg19). Functional classification, and GO enrichment and pathway analyses were performed with the web tool PANTHER (v15.0) (13).

\subsection{Quantitative Real-time Polymerase Chain Reaction}

Total RNA was isolated from myocardium with Trizol reagent according to the manufacturer's instructions (Thermo Fisher). RUNX1 mRNA expression was analyzed with specific primers: 5'-CGGTCGAAGTGGAAGAGGGAA-3' $\quad$ (forward), 5'ATGGCTCTGTGGTAGGTGGC-3' (reverse). Total RNA (12.5 ng) was reverse transcribed and amplified with the iTaq Universal SYBR Green One-Step Kit (Bio-Rad). RUNX1 and ACTB were amplified in parallel in a CFX96 Touch Real-Time PCR Detection System (Bio-Rad) with the following cycling parameters: $50^{\circ} \mathrm{C}$ for $10 \mathrm{~min}$ (reverse transcription), $95^{\circ} \mathrm{C}$ for $1 \mathrm{~min}$, followed by 44 cycles of $95^{\circ} \mathrm{C}$ for $10 \mathrm{~s}, 60.5^{\circ} \mathrm{C}$ for $20 \mathrm{~s}$. Calibration curves were prepared to analyze linearity and PCR efficiency. qRT-PCR data were analyzed using the $\Delta \Delta \mathrm{Ct}$ method with CFX manager Software (Bio-Rad). The $\Delta \mathrm{Ct}$ method was utilized to determine the relative expression of $R U N X 1$ mRNA.

\subsection{Statistical Analyses}

For genome-wide methylation analysis, statistical testing was performed with $R$ using Fisher tests. Statistical significance was set at FDR of 0.05 . $\beta$-values were used to represent the extent of methylation at distinct CpG sites. For RUNX1 mRNA expression analysis, the D'Agostino 
bioRxiv preprint doi: https://doi.org/10.1101/2020.07.15.203075; this version posted July 15, 2020. The copyright holder for this preprint (which was not certified by peer review) is the author/funder, who has granted bioRxiv a license to display the preprint in perpetuity. It is made available under aCC-BY-ND 4.0 International license.

\& Pearson omnibus normality test was used to determine the normality of data sets. Comparisons between means were performed with the Mann-Whitney's U test. 


\section{Results}

\subsection{DNA methylation profiles in myocardial samples}

Data were first preprocessed to remove unreliable probes (1,458 sites), CpG sites containing SNPs (16,928 sites), cross-reactive probes (26,519 sites), and mapping to sex chromosomes (11,295 sites). Following data preprocessing, a total of 429,312 CpG sites were retained for analysis. In general, global methylation profiles of myocardial DNA samples from donors with $(n=12)$ or without DS $(n=12)$ were similar; each myocardial DNA methylation profile showed a bimodal distribution of $\beta$ values, and an average $\beta$ value of 0.45 (Figure 1A). Donor's age and gender had no apparent covariate effects on global myocardial DNA methylation profiles.

3.2. Differentially methylated CpG sites in samples from donors with and without Down syndrome

A total of 192 individual CpG sites were differentially methylated between myocardial DNA samples from subjects with and without DS (FDR < 0.05) (Figure 1B). Of these sites, there were $143 \mathrm{CpG}$ sites with increased methylation in samples with DS relative to samples without DS, whereas $49 \mathrm{CpG}$ sites showed decreased methylation in samples with DS. Analysis of chromosomal locations showed that differentially methylated CpG sites on chromosome 19 were overrepresented and accounted for $15 \%$ of the total (29 sites) (Figure 1B). Of all differentially methylated CpG sites, 93 (48\%) were observed to be highly differentially methylated (absolute $\beta$ value difference in DS versus non-DS groups > 0.100) (Table 1). A total of 15 highly differentially methylated CpG sites were found to be less methylated in myocardial DNA samples with DS relative to samples without DS (average $\beta$ difference $=0.131$ ), whereas $78 \mathrm{CpG}$ sites were more methylated in samples with DS relative to samples without DS (average $\beta$ difference $=0.145$ ). Of the 93 highly differentially methylated CpG sites, 77 (83\%) were distributed in annotated genic regions (i.e., TSS200, TSS1500, 5' UTR, 1st exon, gene body, 3' UTR), and 68 (73\%) were located within $\mathrm{CpG}$ islands (Figure 1C). Genes annotated to differentially methylated CpG sites 
were functionally classified with the PANTHER Classification System (Table S2). For genes with differentially methylated CpG sites and matching protein products, the majority of the hits (25\%) did not match to a specific protein class, and $22 \%$ of the listed proteins did not match to a specific molecular function (Figure 2A).

\subsection{Differentially methylated CpG sites on chromosome 21}

Special attention was given to differentially methylated CpG sites in chromosome 21 and to sites located in the so-called Down syndrome critical region (DSCR, 21q21.1 - q22.2) (14). Eighteen differentially methylated sites were located in chromosome 21 with a total of 6 highly differentially methylated $\mathrm{CpG}$ sites, and 8 differentially methylated CpG sites within the DSCR (Figure 1, and Tables 1 and 2). The mRNA expression of the highly differentially methylated gene RUNX1 (absolute $\beta$ value difference $=0.196$ ) was assessed in samples of total myocardial RNA (Table S3). Samples with matching DNA methylation data from donors with DS $(n=8)$ exhibited higher RUNX1 mRNA expression (4.96 \pm 4.67 relative fold) compared to samples from donors without DS $(\mathrm{n}=12,1.00 \pm 0.67$ relative fold). The inclusion of additional myocardial mRNA samples with no matching DNA methylation data (non-DS, $n=8$, and DS, $n=4$ ) further confirmed the trend towards increased $R U N X 1$ mRNA expression in DS myocardium (DS: $6.73 \pm 6.60$ relative fold, and non-DS: $1.00 \pm 0.89$ relative fold) (Figure 3 ). Linear regression analysis was performed for the group of myocardial samples with matching RUNX1 DNA methylation and mRNA expression data (i.e., DS, $n=8$, and non-DS, $n=12$ ). Linear regression analysis using donor's age and gender as covariates suggest that donor status (i.e., DS and non-DS) and RUNX1 differential methylation expressed as $\beta$ value contribute to a fraction of the variability observed for the expression of the $R U N X 1$ transcript in myocardial tissue $\left(R^{2}=0.61, \operatorname{Adj} R^{2}=\right.$ $0.51, p=0.005$ ). Hypothesis tests on regression coefficients revealed that donor status (DS and non-DS) is significant $(p=0.004)$, although $R U N X 1$ differential methylation was not found to be significant $(p=0.260)$, possibly due to the small sample size. 


\subsection{Differentially methylated regions in DNA samples from donors with and without Down} syndrome

A total of 16 differentially methylated regions (DMR) were identified between samples from donors with and without DS (Table 3). There were no DMR in chromosome 21. DMR overlapped with 30 genes, and DMR with the highest number of $\mathrm{CpG}$ sites included loci in chromosome 6 (37, 32, 27 and 13 CpG sites, respectively), chromosome 22 (14 CpG sites), and chromosome 18 (10 CpG sites). A total of 20 genes mapped to the PANTHER reference list (Table 4). Genes overlapping with DMR identified by the PANTHER classification system included a relatively high proportion of hits with no specific proteins class (55\%), and no assigned molecular function (45\%) (Figure 2B). There was no significant enrichment for gene ontology terms (GO) and molecular pathways. 


\section{Discussion and Conclusions}

This pilot study documents the extent of genome-wide DNA methylation in a collection of samples of myocardial tissue from individuals with and without DS. Persons with DS are at increased risk for the development of various comorbidities which may impact quality of life and mortality rate. The estimated number of people with DS living in the United States was 1 per 1,499 inhabitants in the year 2010 (15). The life expectancy for persons with DS has increased from 9 11 years of age in the 1900 s to over 55 - 60 years of age in the 2000 s, with around $10 \%$ of individuals living now up to 70 years of age $(16,17)$. The myocardial samples analyzed in this study have been obtained from donors representing almost the entire life span of individuals with DS (Table S1). Although donor's age and gender may potentially impact tissular DNA methylation patterns, it was not possible to fully match both sets of samples by age because the DS group included three samples from young donors (ages: 1, 1, and 10 years old) for which there were not age-matched samples from donors without DS (18-20). Nevertheless, the myocardial samples from young donors with DS were maintained for analysis due to the general scarcity of epigenetic data derived from individuals with DS.

Sailani et al. applied reduced representation bisulfite sequencing (RRBS) for the analysis of methylation patterns in DNA from skin fibroblasts from monozygotic twins with and without trisomy 21. The authors found 35 differentially methylated regions (absolute methylation differences $>25 \%$ ) with enrichment in the promoter regions of genes involved in embryonic organ morphogenesis (e.g., HOXB5, HOXB6, HOXD3, and HOXD10). The authors also reported an increase in global DNA methylation in trisomic methylomes in comparison with euploid methylomes (21). RRBS of DNA from placental villi from euploid and trisomic pregnancies showed global hypermethylation in samples with trisomy 21 (22). Our comparisons revealed that global DNA methylation levels are similar in myocardial samples from subjects with and without DS (Figure 1). We identified a relatively small number of differentially methylated CpG sites and 
regions in the myocardial methylomes from donors with DS (Figure 1, and Tables 1 and 3). Thus, it appears that myocardial DNA methylation profiles in the DS context exhibit subtle changes, and differences in DNA methylation levels relative to the non-DS counterpart tend to be localized in a relatively small number of loci. Differentially methylated loci showed no enrichment for GO terms or distinct pathways. In terms of relative methylation at individual $\mathrm{CpG}$ sites, there was a trend towards increased methylation in the DS context with $65.7 \%$ of total differentially methylated $\mathrm{CpG}$ sites and $83.9 \%$ of highly differentially methylated CpG sites showing increased methylation in DS samples in comparison to non-DS samples.

Our analysis identified differential methylation in CpG sites and regions overlapping genes with demonstrated roles in cardiac structure and function (i.e., UNC45A, DNM2), atrioventricular valve formation (i.e., OLFM1), and other cardiac processes including calcium homeostasis, muscle contraction, and cardiac conduction (i.e., DMPK, RYR1) (Table 4 and Table S2) (23-27). Previous studies have noted differential methylation in CpG sites within some of the loci identified in our analysis. For example, differential methylation in KIAA1875, CELSR3, STK19 and UNC45A has been detected in DNA from epithelial cells, placenta, and fetal cortex with trisomy 21 (22, 28, 29). Likewise, we identified a number of highly differentially methylated sites located within the KIAA1875, CELSR3, STK19, and UNC45A loci (3, 5, 6, and 4 CpG sites, respectively), all of them showing increased methylation in myocardial DNA from donors with DS (Table 1).

Our study identified $8 \mathrm{CpG}$ sites within the so called DSCR which were differentially methylated in DS myocardium. The DSCR included a highly differentially methylated CpG site within the RUNX1 locus (Table 2). On average, RUNX1 mRNA expression in trisomic myocardium was 6-fold higher than in diploid tissue, although there was considerable interindividual variability (SD: 6-fold) (Figure 3). RUNX family members form heterodimeric transcription factors that activate or repress gene transcription in healthy and disease states. Little is known regarding the roles of RUNX factors during cardiac physiology. A recent study in a murine model showed that 
Runx1 modulates calcium ion uptake in sarcoplasmic reticulum and cardiac contractility. Of note, reduction of Runx1 function prevented adverse cardiac remodeling after myocardial infarction (30). Our simple linear regression model based on donors' age, gender, DS status, and RUNX1 methylation suggests that these variables may contribute up to $\sim 51 \%$ of the variability in myocardial RUNX1 mRNA expression. Although DS status was found to be a strong predictor of RUNX1 mRNA methylation, RUNX1 interindividual methylation did not reach the level of significance per se. We hypothesize that this is due in part to the small sample size, which is a limitation for the linear regression. Elucidation of the role of differential $R U N X 1$ methylation during myocardial function in the context of DS deserves further investigation.

Many of the "genes" overlapping with differentially methylated CpG sites and DMR had unknown function and/or protein-coding potential, or codify non-protein products (Figure 2, Table 4). Only $58 \%$ of the genes overlapping with DMR codify for proteins with known functions, and around $24 \%$ codify non-coding RNAs. Differential expression of non-coding RNA species has been detected in human trisomic endothelial progenitor cells and induced pluripotent stem cells $(31,32)$. Many non-coding RNAs regulate complex biological functions and are involved in disease processes such as cardiovascular disease $(33,34)$. For example, our data suggest that RNARP11-344E13.3 is differentially methylated in DS myocardium. RNARP11-344E13.3 is a long non-coding RNA that interacts with microRNA targets linked to the development of cardiac hypertrophy (35). It would be of interest to further investigate the role of differential DNA methylation during the expression of non-coding RNAs in myocardium with emphasis on the DS setting.

This pilot study is limited by the small number of myocardial samples from donors with and without DS. Although our analysis identified a number of differentially methylated loci in DS myocardium, these observations need to be confirmed in larger sample sizes. Research on fundamental issues concerning the pathobiology of DS continues to be hampered by the scarcity 
of good quality tissue samples from donors with DS. We believe that this study provides an initial snapshot on the extent of genome-wide differential methylation in myocardial tissue from persons with DS. This study contributes new data to further examine the contribution of differential DNA methylation to the complex pathobiology of DS.

\section{REFERENCES}

1. Oster-Granite ML, Parisi MA, Abbeduto L, Berlin DS, Bodine C, Bynum D, Capone G, Collier E, Hall $D$, Kaeser L, Kaufmann P, Krischer J, Livingston M, McCabe LL, Pace J, Pfenninger K, Rasmussen SA, Reeves RH, Rubinstein Y, Sherman S, Terry SF, Whitten MS, Williams S, McCabe ER, Maddox YT. Down syndrome: national conference on patient registries, research databases, and biobanks. Mol Genet Metab. 2011;104(1-2):13-22. Epub 2011/08/13. doi: 10.1016/j.ymgme.2011.07.005. PubMed PMID: $21835664 ;$ PMCID: PMC3171614.

2. Stoll C, Dott B, Alembik Y, Roth MP. Associated congenital anomalies among cases with Down syndrome. Eur J Med Genet. 2015;58(12):674-80. Epub 2015/11/19. doi: 10.1016/j.ejmg.2015.11.003. PubMed PMID: 26578241.

3. Weijerman ME, van Furth $A M$, van der Mooren MD, van Weissenbruch MM, Rammeloo L, Broers CJ, Gemke RJ. Prevalence of congenital heart defects and persistent pulmonary hypertension of the neonate with Down syndrome. Eur J Pediatr. 2010;169(10):1195-9. Epub 2010/04/23. doi: 10.1007/s00431-010-1200-0. PubMed PMID: 20411274; PMCID: PMC2926442.

4. Freeman SB, Bean LH, Allen EG, Tinker SW, Locke AE, Druschel C, Hobbs CA, Romitti PA, Royle $\mathrm{MH}$, Torfs CP, Dooley KJ, Sherman SL. Ethnicity, sex, and the incidence of congenital heart defects: a report from the National Down Syndrome Project. Genet Med. 2008;10(3):173-80. Epub 2008/03/18. doi: 10.1097/GIM.0b013e3181634867. PubMed PMID: 18344706.

5. Jones PA. Functions of DNA methylation: islands, start sites, gene bodies and beyond. Nat Rev Genet. 2012;13(7):484-92. Epub 2012/05/30. doi: 10.1038/nrg3230

nrg3230 [pii]. PubMed PMID: 22641018.

6. Serra-Juhe C, Cusco I, Homs A, Flores R, Toran N, Perez-Jurado LA. DNA methylation abnormalities in congenital heart disease. Epigenetics. 2015;10(2):167-77. Epub 2015/01/15. doi: 10.1080/15592294.2014.998536. PubMed PMID: 25587870; PMCID: PMC4622722.

7. Hefti E, Quinones-Lombrana A, Redzematovic A, Hui J, Blanco JG. Analysis of mtDNA, miR-155 and BACH1 expression in hearts from donors with and without Down syndrome. Mitochondrial DNA A DNA Mapp Seq Anal. 2016;27(2):896-903. Epub 2014/06/19. doi: 10.3109/19401736.2014.926477. PubMed PMID: 24938108; PMCID: PMC4315749.

8. Carless MA. Determination of DNA methylation levels using Illumina HumanMethylation450 BeadChips. Methods Mol Biol. 2015;1288:143-92. Epub 2015/04/02. doi: 10.1007/978-1-4939-24745_10. PubMed PMID: 25827880.

9. Aryee MJ, Jaffe AE, Corrada-Bravo H, Ladd-Acosta C, Feinberg AP, Hansen KD, Irizarry RA. Minfi: a flexible and comprehensive Bioconductor package for the analysis of Infinium DNA methylation microarrays. Bioinformatics. 2014;30(10):1363-9. Epub 2014/01/31. doi: 10.1093/bioinformatics/btu049. PubMed PMID: 24478339; PMCID: PMC4016708. 
10. Assenov Y, Muller F, Lutsik P, Walter J, Lengauer T, Bock C. Comprehensive analysis of DNA methylation data with RnBeads. Nat Methods. 2014;11(11):1138-40. Epub 2014/09/30. doi: 10.1038/nmeth.3115. PubMed PMID: 25262207; PMCID: PMC4216143.

11. Chen YA, Lemire M, Choufani S, Butcher DT, Grafodatskaya D, Zanke BW, Gallinger S, Hudson TJ, Weksberg R. Discovery of cross-reactive probes and polymorphic CpGs in the Illumina Infinium HumanMethylation450 microarray. Epigenetics. 2013;8(2):203-9. Epub 2013/01/15. doi: 10.4161/epi.23470. PubMed PMID: 23314698; PMCID: PMC3592906.

12. Peters TJ, Buckley MJ, Statham AL, Pidsley R, Samaras K, R VL, Clark SJ, Molloy PL. De novo identification of differentially methylated regions in the human genome. Epigenetics Chromatin. 2015;8:6. Epub 2015/05/15. doi: 10.1186/1756-8935-8-6. PubMed PMID: 25972926; PMCID: PMC4429355.

13. Mi H, Muruganujan A, Ebert D, Huang X, Thomas PD. PANTHER version 14: more genomes, a new PANTHER GO-slim and improvements in enrichment analysis tools. Nucleic Acids Res. 2019;47(D1):D419-D26. Epub 2018/11/09. doi: 10.1093/nar/gky1038. PubMed PMID: 30407594; PMCID: PMC6323939.

14. Sinet PM, Theophile D, Rahmani Z, Chettouh Z, Blouin JL, Prieur M, Noel B, Delabar JM. Mapping of the Down syndrome phenotype on chromosome 21 at the molecular level. Biomed Pharmacother. 1994;48(5-6):247-52. Epub 1994/01/01. doi: 10.1016/0753-3322(94)90140-6. PubMed PMID: 7999986. 15. de Graaf G, Buckley F, Skotko BG. Estimation of the number of people with Down syndrome in the United States. Genet Med. 2017;19(4):439-47. Epub 2016/09/09. doi: 10.1038/gim.2016.127. PubMed PMID: 27608174.

16. Brown R, Taylor J, Matthews B. Quality of life--ageing and Down syndrome. Downs Syndr Res Pract. 2001;6(3):111-6. Epub 2001/08/15. doi: 10.3104/case-studies.101. PubMed PMID: 11501212. 17. Head E, Lott IT, Wilcock DM, Lemere CA. Aging in Down Syndrome and the Development of Alzheimer's Disease Neuropathology. Curr Alzheimer Res. 2016;13(1):18-29. Epub 2015/12/15. doi: 10.2174/1567205012666151020114607. PubMed PMID: 26651341; PMCID: PMC4948181.

18. Boks MP, Derks EM, Weisenberger DJ, Strengman E, Janson E, Sommer IE, Kahn RS, Ophoff RA. The relationship of DNA methylation with age, gender and genotype in twins and healthy controls. PLoS One. 2009;4(8):e6767. Epub 2009/09/24. doi: 10.1371/journal.pone.0006767. PubMed PMID:

19774229; PMCID: PMC2747671.

19. Illi B, Ciarapica R, Capogrossi MC. Chromatin methylation and cardiovascular aging. J Mol Cell Cardiol. 2015;83:21-31. Epub 2015/03/01. doi: 10.1016/j.yjmcc.2015.02.011. PubMed PMID: 25724723. 20. Zampieri M, Ciccarone F, Calabrese R, Franceschi C, Burkle A, Caiafa P. Reconfiguration of DNA methylation in aging. Mech Ageing Dev. 2015;151:60-70. Epub 2015/02/25. doi: 10.1016/j.mad.2015.02.002. PubMed PMID: 25708826.

21. Sailani MR, Santoni FA, Letourneau A, Borel C, Makrythanasis P, Hibaoui $Y$, Popadin K, Bonilla X, Guipponi M, Gehrig C, Vannier A, Carre-Pigeon F, Feki A, Nizetic D, Antonarakis SE. DNA-Methylation Patterns in Trisomy 21 Using Cells from Monozygotic Twins. PLoS One. 2015;10(8):e0135555. Epub 2015/09/01. doi: 10.1371/journal.pone.0135555. PubMed PMID: 26317209; PMCID: PMC4552626. 22. Jin S, Lee YK, Lim YC, Zheng Z, Lin XM, Ng DP, Holbrook JD, Law HY, Kwek KY, Yeo GS, Ding C. Global DNA hypermethylation in down syndrome placenta. PLoS Genet. 2013;9(6):e1003515. Epub 2013/06/12. doi: 10.1371/journal.pgen.1003515. PubMed PMID: 23754950; PMCID: PMC3675012.

23. Lee CF, Melkani GC, Bernstein SI. The UNC-45 myosin chaperone: from worms to flies to vertebrates. Int Rev Cell Mol Biol. 2014;313:103-44. Epub 2014/11/08. doi: 10.1016/B978-0-12-8001776.00004-9. PubMed PMID: 25376491; PMCID: PMC4225561.

24. Li J, Zhang DS, Ye JC, Li CM, Qi M, Liang DD, Xu XR, Xu L, Liu Y, Zhang H, Zhang YY, Deng FF, Feng J, Shi D, Chen JJ, Li L, Chen G, Sun YF, Peng LY, Chen YH. Dynamin-2 mediates heart failure by modulating 
Ca2+ -dependent cardiomyocyte apoptosis. Int J Cardiol. 2013;168(3):2109-19. Epub 2013/02/16. doi: 10.1016/j.ijcard.2013.01.006. PubMed PMID: 23410488.

25. Lencinas A, Chhun DC, Dan KP, Ross KD, Hoover EA, Antin PB, Runyan RB. Olfactomedin-1 activity identifies a cell invasion checkpoint during epithelial-mesenchymal transition in the chick embryonic heart. Dis Model Mech. 2013;6(3):632-42. Epub 2012/12/25. doi: 10.1242/dmm.010595. PubMed PMID: 23264563; PMCID: PMC3634647.

26. Kaliman P, Catalucci D, Lam JT, Kondo R, Gutierrez JC, Reddy S, Palacin M, Zorzano A, Chien KR, Ruiz-Lozano P. Myotonic dystrophy protein kinase phosphorylates phospholamban and regulates calcium uptake in cardiomyocyte sarcoplasmic reticulum. J Biol Chem. 2005;280(9):8016-21. Epub 2004/12/16. doi: 10.1074/jbc.M412845200. PubMed PMID: 15598648.

27. Lawal TA, Todd JJ, Meilleur KG. Ryanodine Receptor 1-Related Myopathies: Diagnostic and Therapeutic Approaches. Neurotherapeutics. 2018;15(4):885-99. Epub 2018/11/09. doi: 10.1007/s13311-018-00677-1. PubMed PMID: 30406384; PMCID: PMC6277304.

28. El Hajj N, Dittrich M, Bock J, Kraus TF, Nanda I, Muller T, Seidmann L, Tralau T, Galetzka D, Schneider E, Haaf T. Epigenetic dysregulation in the developing Down syndrome cortex. Epigenetics. 2016;11(8):563-78. Epub 2016/06/02. doi: 10.1080/15592294.2016.1192736. PubMed PMID: 27245352; PMCID: PMC4990229.

29. Jones MJ, Farre P, McEwen LM, Macisaac JL, Watt K, Neumann SM, Emberly E, Cynader MS, VirjiBabul N, Kobor MS. Distinct DNA methylation patterns of cognitive impairment and trisomy 21 in Down syndrome. BMC Med Genomics. 2013;6:58. Epub 2014/01/01. doi: 10.1186/1755-8794-6-58. PubMed PMID: 24373378; PMCID: PMC3879645.

30. McCarroll CS, He W, Foote K, Bradley A, McGlynn K, Vidler F, Nixon C, Nather K, Fattah C, Riddell A, Bowman P, Elliott EB, Bell M, Hawksby C, MacKenzie SM, Morrison LJ, Terry A, Blyth K, Smith GL, McBride MW, Kubin T, Braun T, Nicklin SA, Cameron ER, Loughrey CM. Runx1 Deficiency Protects Against Adverse Cardiac Remodeling After Myocardial Infarction. Circulation. 2018;137(1):57-70. Epub 2017/10/17. doi: 10.1161/CIRCULATIONAHA.117.028911. PubMed PMID: 29030345; PMCID: PMC5757664.

31. Costa V, Angelini C, D'Apice L, Mutarelli M, Casamassimi A, Sommese L, Gallo MA, Aprile M, Esposito R, Leone L, Donizetti A, Crispi S, Rienzo M, Sarubbi B, Calabro R, Picardi M, Salvatore P, Infante T, De Berardinis P, Napoli C, Ciccodicola A. Massive-scale RNA-Seq analysis of non ribosomal transcriptome in human trisomy 21. PLoS One. 2011;6(4):e18493. Epub 2011/05/03. doi: 10.1371/journal.pone.0018493. PubMed PMID: 21533138; PMCID: PMC3080369.

32. Qiu JJ, Liu YN, Ren ZR, Yan JB. Dysfunctions of mitochondria in close association with strong perturbation of long noncoding RNAs expression in down syndrome. Int J Biochem Cell Biol. 2017;92:115-20. Epub 2017/10/03. doi: 10.1016/j.biocel.2017.09.017. PubMed PMID: 28965985.

33. Elia L, Condorelli G. RNA (Epi)genetics in cardiovascular diseases. J Mol Cell Cardiol. 2015;89(Pt A):11-6. Epub 2015/07/25. doi: 10.1016/j.yjmcc.2015.07.012. PubMed PMID: 26205296.

34. Ounzain S, Burdet F, Ibberson M, Pedrazzini T. Discovery and functional characterization of cardiovascular long noncoding RNAs. J Mol Cell Cardiol. 2015;89(Pt A):17-26. Epub 2015/09/27. doi: 10.1016/j.yjmcc.2015.09.013. PubMed PMID: 26408097.

35. Song C, Zhang J, Liu Y, Pan H, Qi HP, Cao YG, Zhao JM, Li S, Guo J, Sun HL, Li CQ. Construction and analysis of cardiac hypertrophy-associated IncRNA-mRNA network based on competitive endogenous RNA reveal functional IncRNAs in cardiac hypertrophy. Oncotarget. 2016;7(10):10827-40. Epub 2016/02/13. doi: 10.18632/oncotarget.7312. PubMed PMID: 26872060; PMCID: PMC4905442. 


\section{Funding}

This study was supported by the National Cancer Institute (award R21CA245067) and the National Institute of General Medical Sciences (award R01GM073646).

\section{Declaration of competing interest}

The authors declare that they have no known competing financial interests or personal relationships that could have appeared to influence the work reported in this paper.

\section{Figure legends}

Figure 1. Differential methylation in myocardial DNA from donors with DS. A) Density plots of DNA methylation levels ( $\beta$ values) in myocardial DNA from donors with and without DS (DS, $n=$ 12 , and non-DS, $n=12)$. B) $P$ values (- $\log 10)$ of differentially methylated $C p G$ sites stratified by chromosomal location. The blue line depicts the threshold for statistical significance (FDR = 0.05).

C) Location of differentially methylated sites in relation to functional subregions (left panel) and CpG islands (right panel).

Figure 2. PANTHER functional classification. A) Classification of genes mapped to differentially methylated CpG sites. B) Classification of genes mapped to differentially methylated regions (DMR). Top panels: protein class, middle panels: molecular function, and bottom panels: biological processes. Genes without hits are listed as non-classified.

Figure 3. Relative $R U N X 1 \mathrm{mRNA}$ fold expression in myocardial samples from donors without and with DS (non-DS, $n=16$, and $D S, n=16$ ). Black dots represent additional myocardial mRNA samples from donors without (8 mRNA samples) and with DS (4 mRNA samples) with no matching DNA methylation data. Each point represents the mean from three separate measurements performed in triplicates. Horizontal bars show the mean $\pm S D$. ${ }^{* *} P<0.001$, Mann Whitney test. 
bioRxiv preprint doi: https://doi.org/10.1101/2020.07.15.203075; this version posted July 15, 2020. The copyright holder for this preprint (which

was not certified by peer review) is the author/funder, who has granted bioRxiv a license to display the preprint in perpetuity. It is made available under aCC-BY-ND 4.0 International license.

Table 1. Highly differentially methylated CpG sites in myocardial DNA from subjects with DS.

Table 2. Differentially methylated sites within the DSCR in myocardial DNA from subjects with DS.

Table 3. Differentially methylated regions in myocardial DNA from subjects with DS.

Table 4. Genes showing overlap with DMR in myocardial DNA from subjects with DS. Functional classification according to the PANTHER classification system. 


\section{Protein class (Differentially methylated sites)}

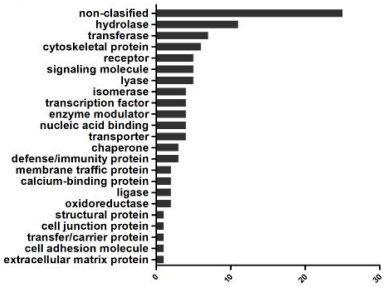

Gene hit' total genes (\%)

Molecular function (Differentially methylated sites)

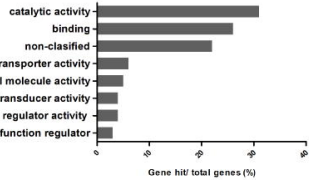

\section{Biological process (Differentially methylated sites)} cellular process
metabolic process
localization

biological regulation

response to stimulus immune system process

biological adhesion

developmental process reproduction cell comp organization/biogenesis -

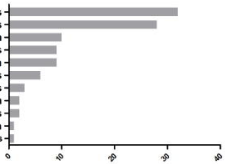

Gene hit total genes (\%)

\section{Protein class (DMR)}

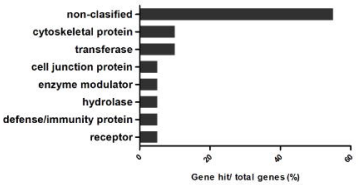

Molecular function (DMR)

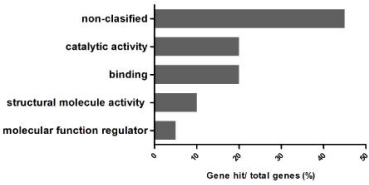

\section{Biological process (DMR)}

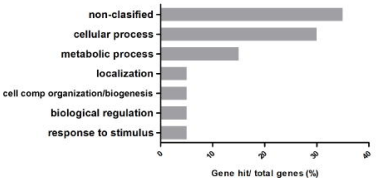




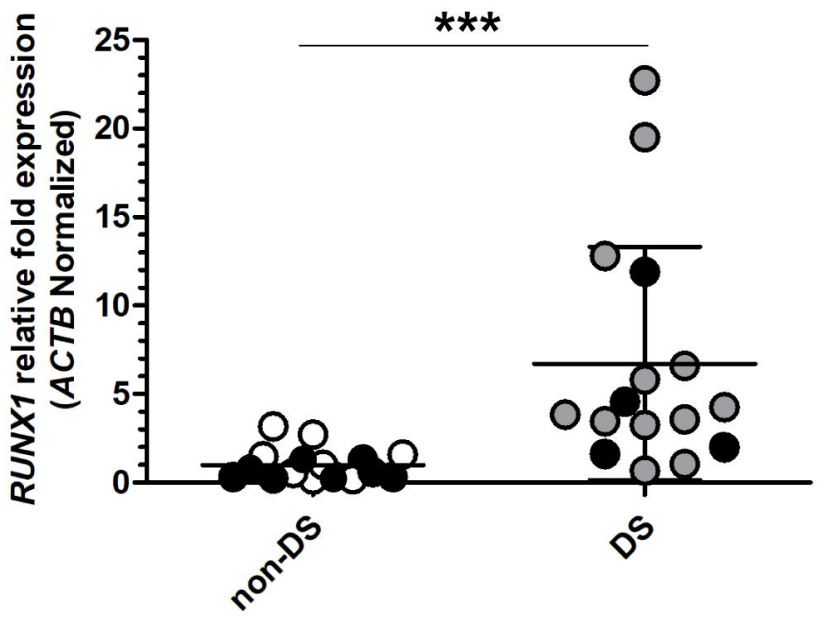


Table 1. Highly differentially methylated CpG sites in myocardial DNA from subjects with DS.

\begin{tabular}{|c|c|c|c|c|c|c|c|c|}
\hline ID & Chromosome & $\begin{array}{l}\text { Relation to } \\
\text { Island }\end{array}$ & $\begin{array}{c}\text { UCSC } \\
\text { Reference } \\
\text { Gene Name }\end{array}$ & $\begin{array}{c}\text { UCSC } \\
\text { Reference } \\
\text { Gene Group }\end{array}$ & $\begin{array}{c}\text { adj. } \\
\text { P.Value }\end{array}$ & $\begin{array}{c}\beta \text {-value } \\
\text { NDS }\end{array}$ & $\begin{array}{c}\beta \text {-value } \\
\text { DS }\end{array}$ & $\Delta \beta$-value \\
\hline $\operatorname{cg} 04094791$ & chr01 & Island & HSPA7 & Body & $6.24 E-03$ & 0.59 & 0.73 & -0.135 \\
\hline $\operatorname{cg} 05304531$ & chr01 & N_Shore & $\begin{array}{l}\text { DHDDS;HM } \\
\text { GN2 }\end{array}$ & 3'UTR;TSS1500 & $3.35 \mathrm{E}-02$ & 0.54 & 0.64 & -0.105 \\
\hline $\operatorname{cg} 18139641$ & chr01 & OpenSea & CSRP1 & 5'UTR & 3.67E-02 & 0.71 & 0.60 & 0.114 \\
\hline $\operatorname{cg} 06940110$ & chr02 & N_Shore & & & 3.69E-02 & 0.40 & 0.57 & -0.163 \\
\hline $\operatorname{cg} 14515364$ & chro2 & Island & & & 7.29E-04 & 0.64 & 0.78 & -0.140 \\
\hline $\operatorname{cg} 03223076$ & chr03 & Island & CELSR3 & 1stExon & $1.08 \mathrm{E}-02$ & 0.48 & 0.69 & -0.209 \\
\hline $\operatorname{cg} 02222844$ & chr03 & Island & CELSR3 & Body & 4.21E-02 & 0.48 & 0.65 & -0.178 \\
\hline $\operatorname{cg} 02773588$ & chr03 & Island & CELSR3 & 1stExon & $2.04 \mathrm{E}-03$ & 0.62 & 0.79 & -0.162 \\
\hline cg08640901 & chr03 & Island & CELSR3 & Body & 4.32E-03 & 0.47 & 0.59 & -0.116 \\
\hline $\operatorname{cg} 15142694$ & chr03 & Island & CELSR3 & Body & 4.85E-02 & 0.64 & 0.74 & -0.103 \\
\hline cg12477903 & chr05 & Island & F12 & Body & $8.30 \mathrm{E}-05$ & 0.18 & 0.31 & -0.127 \\
\hline cg04149916 & chr06 & N_Shore & $\begin{array}{l}\text { STK19;STK1 } \\
\text { 9;DOM3Z }\end{array}$ & $\begin{array}{l}\text { TSS1500;TSS1 } \\
\text { 500;Body }\end{array}$ & $2.58 \mathrm{E}-04$ & 0.32 & 0.48 & -0.162 \\
\hline $\operatorname{cg} 20194050$ & chr06 & N_Shore & $\begin{array}{l}\text { STK19;STK1 } \\
\text { 9;DOM3Z }\end{array}$ & $\begin{array}{l}\text { TSS1500;TSS1 } \\
\text { 500;Body }\end{array}$ & 9.99E-03 & 0.54 & 0.69 & -0.150 \\
\hline $\operatorname{cg} 13069441$ & chr06 & N_Shore & $\begin{array}{l}\text { STK19;STK1 } \\
\text { 9;DOM3Z }\end{array}$ & $\begin{array}{l}\text { TSS1500;TSS1 } \\
\text { 500;Body }\end{array}$ & $8.85 \mathrm{E}-03$ & 0.37 & 0.52 & -0.147 \\
\hline $\operatorname{cg} 23906067$ & chr06 & N_Shore & $\begin{array}{l}\text { STK19;STK1 } \\
\text { 9;DOM3Z }\end{array}$ & $\begin{array}{l}\text { TSS1500;TSS1 } \\
\text { 500;Body }\end{array}$ & $1.12 \mathrm{E}-02$ & 0.38 & 0.52 & -0.141 \\
\hline $\operatorname{cg} 18319852$ & chr06 & S_Shore & KIF25 & Body & $3.56 \mathrm{E}-02$ & 0.34 & 0.48 & -0.138 \\
\hline cg26077005 & chr06 & OpenSea & & & 4.21E-02 & 0.50 & 0.62 & -0.118 \\
\hline cg10914467 & chr06 & N_Shore & $\begin{array}{l}\text { STK19;STK1 } \\
\text { 9;DOM3Z }\end{array}$ & $\begin{array}{l}\text { TSS1500;TSS1 } \\
\text { 500;Body }\end{array}$ & $1.92 \mathrm{E}-02$ & 0.32 & 0.44 & -0.117 \\
\hline $\operatorname{cg} 26968378$ & chr06 & OpenSea & & & 4.45E-02 & 0.28 & 0.39 & -0.117 \\
\hline cg16190718 & chr06 & N_Shore & $\begin{array}{l}\text { STK19;STK1 } \\
\text { 9;DOM3Z }\end{array}$ & $\begin{array}{l}\text { TSS1500;TSS1 } \\
\text { 500;Body }\end{array}$ & $3.94 \mathrm{E}-02$ & 0.38 & 0.48 & -0.103 \\
\hline $\operatorname{cg} 10052687$ & chr07 & N_Shelf & CLIP2 & Body & 4.32E-03 & 0.53 & 0.43 & 0.102 \\
\hline cg21243198 & chr07 & S_Shelf & HEATR2 & Body & $5.21 \mathrm{E}-03$ & 0.79 & 0.66 & 0.128 \\
\hline $\operatorname{cg} 25468618$ & chr08 & Island & FAM83H & Body & 4.87E-06 & 0.54 & 0.77 & -0.223 \\
\hline cg13735469 & chr08 & Island & FAM83H & Body & 7.42E-04 & 0.50 & 0.70 & -0.193 \\
\hline cg26272248 & chr08 & N_Shore & KIAA1875 & Body & $3.75 \mathrm{E}-02$ & 0.45 & 0.63 & -0.178 \\
\hline $\operatorname{cg} 01399317$ & chr08 & Island & FAM83H & Body & $2.54 \mathrm{E}-04$ & 0.59 & 0.77 & -0.171 \\
\hline cg07962934 & chr08 & Island & FAM83H & Body & 2.49E-05 & 0.67 & 0.84 & -0.163 \\
\hline cg01612292 & chr08 & Island & FAM83H & Body & 1.89E-12 & 0.77 & 0.92 & -0.145 \\
\hline cg24063962 & chr08 & Island & $\begin{array}{l}\text { LOC1001302 } \\
74\end{array}$ & TSS200 & $1.26 \mathrm{E}-02$ & 0.42 & 0.55 & -0.129 \\
\hline $\operatorname{cg} 02601489$ & chr08 & N_Shore & TDH & Body & 1.33E-02 & 0.41 & 0.54 & -0.128 \\
\hline cg18925846 & chr08 & Island & KIAA1875 & Body & $1.26 \mathrm{E}-02$ & 0.69 & 0.81 & -0.121 \\
\hline cg21429107 & chr08 & Island & $\begin{array}{l}\text { LOC1001302 } \\
74\end{array}$ & TSS200 & 9.99E-03 & 0.34 & 0.46 & -0.119 \\
\hline $\operatorname{cg} 01423393$ & chr08 & Island & KIAA1875 & Body & 4.53E-03 & 0.49 & 0.61 & -0.117 \\
\hline cg05358723 & chr08 & Island & $\begin{array}{l}\text { LRRC24;LR } \\
\text { RC14 }\end{array}$ & Body;3'UTR & $1.06 \mathrm{E}-02$ & 0.41 & 0.51 & -0.101 \\
\hline $\operatorname{cg} 09381737$ & chrog & Island & C9orf167 & Body & 4.10E-02 & 0.55 & 0.68 & -0.129 \\
\hline $\operatorname{cg} 04471485$ & chr09 & Island & CLIC3 & Body & 3.63E-03 & 0.32 & 0.44 & -0.116 \\
\hline cg14147184 & chrog & Island & OLFM1 & Body & $1.45 \mathrm{E}-02$ & 0.56 & 0.44 & 0.120 \\
\hline $\operatorname{cg} 19511338$ & chr10 & N_Shore & & & 4.81E-02 & 0.56 & 0.66 & -0.107 \\
\hline $\operatorname{cg} 02493211$ & chr11 & Island & BCL9L & TSS200 & 4.43E-02 & 0.38 & 0.58 & -0.196 \\
\hline $\operatorname{cg} 01425746$ & chr11 & Island & CHST1 & Body & $9.94 \mathrm{E}-03$ & 0.66 & 0.79 & -0.131 \\
\hline cg24985772 & chr11 & Island & & & 4.08E-02 & 0.36 & 0.49 & -0.129 \\
\hline cg06938878 & chr11 & N_Shore & CALCB & TSS1500 & $6.24 \mathrm{E}-03$ & 0.62 & 0.72 & -0.102 \\
\hline cg10287786 & chr11 & N_Shore & DSCAML1 & Body & 1.69E-02 & 0.75 & 0.61 & 0.140 \\
\hline $\operatorname{cg} 03434624$ & $\operatorname{chr} 12$ & Island & VPS37B & TSS200 & $3.10 \mathrm{E}-02$ & 0.19 & 0.32 & -0.131 \\
\hline cg17566325 & chr12 & N_Shore & & & $3.16 \mathrm{E}-02$ & 0.40 & 0.28 & 0.114 \\
\hline
\end{tabular}




\begin{tabular}{|c|c|c|c|c|c|c|c|c|}
\hline $\operatorname{cg} 26352652$ & chr12 & N_Shore & & & $4.08 \mathrm{E}-02$ & 0.49 & 0.35 & 0.147 \\
\hline cg01863042 & chr13 & OpenSea & & & $7.00 \mathrm{E}-03$ & 0.46 & 0.58 & -0.128 \\
\hline cg07980777 & chr13 & OpenSea & N6AMT2 & 3'UTR & $3.78 \mathrm{E}-03$ & 0.71 & 0.59 & 0.121 \\
\hline cg01351822 & chr15 & Island & $\begin{array}{l}\text { UNC45A;UN } \\
\text { C45A }\end{array}$ & 5'UTR;1 stExon & $8.85 \mathrm{E}-03$ & 0.12 & 0.34 & -0.223 \\
\hline $\operatorname{cg} 13778201$ & chr15 & Island & UNC45A & TSS200 & $4.21 \mathrm{E}-02$ & 0.28 & 0.46 & -0.177 \\
\hline cg08551047 & chr15 & Island & UNC45A & 5'UTR & $8.85 \mathrm{E}-03$ & 0.21 & 0.33 & -0.124 \\
\hline $\operatorname{cg} 16414568$ & chr15 & Island & UNC45A & 5'UTR & 3.48E-03 & 0.10 & 0.20 & -0.107 \\
\hline cg02156899 & chr16 & Island & NOXO1 & Body & $8.30 \mathrm{E}-05$ & 0.42 & 0.63 & -0.211 \\
\hline cg02649063 & chr16 & Island & CES4 & Body & 3.22E-02 & 0.39 & 0.60 & -0.202 \\
\hline cg04599341 & chr16 & Island & NOXO1 & Body & 3.45E-06 & 0.40 & 0.56 & -0.163 \\
\hline cg09465703 & chr16 & Island & JMJD8 & Body & $6.19 \mathrm{E}-03$ & 0.14 & 0.29 & -0.151 \\
\hline cg17300750 & chr16 & Island & DNASE1L2 & Body & $1.88 \mathrm{E}-02$ & 0.27 & 0.39 & -0.122 \\
\hline cg00029825 & chr16 & Island & SLC5A2 & Body & $2.65 \mathrm{E}-03$ & 0.60 & 0.71 & -0.111 \\
\hline cg05673293 & chr16 & N_Shore & & & $1.26 \mathrm{E}-02$ & 0.49 & 0.59 & -0.108 \\
\hline cg14560110 & chr17 & Island & CCDC144NL & TSS200 & 7.42E-04 & 0.51 & 0.74 & -0.237 \\
\hline cg22570042 & chr17 & Island & CCDC144NL & TSS200 & $1.24 \mathrm{E}-02$ & 0.57 & 0.73 & -0.160 \\
\hline cg06809326 & chr17 & Island & CCDC144NL & TSS200 & $3.63 \mathrm{E}-03$ & 0.59 & 0.74 & -0.152 \\
\hline cg21980100 & chr17 & Island & CCDC144NL & TSS200 & $3.52 \mathrm{E}-02$ & 0.32 & 0.42 & -0.103 \\
\hline cg13704680 & chr18 & Island & $\begin{array}{l}\text { LOC1001305 } \\
22\end{array}$ & TSS1500 & 4.21E-02 & 0.34 & 0.18 & 0.152 \\
\hline $\operatorname{cg} 05251669$ & chr18 & Island & LOC1001305 & TSS1500 & $4.45 \mathrm{E}-02$ & 0.44 & 0.28 & 0.162 \\
\hline cg02452966 & chr19 & Island & RYR1 & Body & $3.10 \mathrm{E}-02$ & 0.32 & 0.60 & -0.278 \\
\hline cg02749105 & chr19 & Island & ZNF837 & 3'UTR & $7.76 \mathrm{E}-03$ & 0.34 & 0.56 & -0.212 \\
\hline cg24052338 & chr19 & Island & ZNF837 & 3'UTR & 3.69E-02 & 0.47 & 0.67 & -0.193 \\
\hline cg09594291 & chr19 & Island & ZNF837 & 3'UTR & $2.16 \mathrm{E}-02$ & 0.26 & 0.45 & -0.192 \\
\hline cg05317207 & chr19 & Island & ZNF497 & Body & $3.97 \mathrm{E}-03$ & 0.22 & 0.39 & -0.174 \\
\hline cg00879218 & chr19 & Island & & & $2.04 \mathrm{E}-03$ & 0.47 & 0.63 & -0.167 \\
\hline cg26659805 & chr19 & Island & AMH & Body & $6.19 \mathrm{E}-03$ & 0.19 & 0.34 & -0.147 \\
\hline cg02452418 & chr19 & Island & RYR1 & Body & 4.21E-02 & 0.16 & 0.31 & -0.146 \\
\hline cg08504662 & chr19 & Island & ZNF497 & Body & 4.45E-02 & 0.21 & 0.35 & -0.143 \\
\hline cg03598159 & chr19 & Island & RYR1 & Body & $3.68 \mathrm{E}-02$ & 0.17 & 0.30 & -0.130 \\
\hline cg11707067 & chr19 & Island & $\begin{array}{l}\text { MZF1;LOC1 } \\
00131691\end{array}$ & 3'UTR;Body & $3.65 \mathrm{E}-02$ & 0.65 & 0.78 & -0.129 \\
\hline cg08095654 & chr19 & Island & & & $1.12 \mathrm{E}-02$ & 0.44 & 0.55 & -0.110 \\
\hline cg08084812 & chr19 & Island & ZNF837 & Body & $1.33 \mathrm{E}-02$ & 0.67 & 0.78 & -0.110 \\
\hline cg22914897 & chr19 & Island & $\begin{array}{l}\text { MZF1;:LOC1 } \\
00131691\end{array}$ & 3'UTR;Body & $7.29 \mathrm{E}-04$ & 0.69 & 0.79 & -0.106 \\
\hline $\operatorname{cg} 18154954$ & chr19 & Island & RYR1 & Body & $1.83 \mathrm{E}-02$ & 0.64 & 0.75 & -0.105 \\
\hline cg08620751 & chr19 & Island & & & $3.78 \mathrm{E}-03$ & 0.46 & 0.56 & -0.103 \\
\hline cg20285546 & chr19 & Island & & & 4.77E-02 & 0.41 & 0.51 & -0.101 \\
\hline cg13382072 & chr19 & Island & & & 3.68E-02 & 0.36 & 0.46 & -0.101 \\
\hline cg15820033 & chr19 & Island & PTPRS & Body & $8.72 \mathrm{E}-03$ & 0.38 & 0.26 & 0.117 \\
\hline cg23796967 & chr19 & OpenSea & GP6 & $1 \mathrm{stExon}$ & 7.29E-04 & 0.60 & 0.47 & 0.127 \\
\hline cg05267394 & chr20 & Island & ASIP & Body & 3.22E-02 & 0.38 & 0.23 & 0.152 \\
\hline cg00994804 & chr21 & Island & $\begin{array}{l}\text { RUNX1; RUN } \\
\text { X1 }\end{array}$ & 1stExon;Body & $5.89 \mathrm{E}-03$ & 0.12 & 0.32 & -0.196 \\
\hline $\operatorname{cg} 00949980$ & chr21 & Island & SUMO3 & Body & $2.54 \mathrm{E}-02$ & 0.53 & 0.68 & -0.148 \\
\hline cg07397296 & chr21 & Island & ABCG1 & Body & 3.65E-02 & 0.14 & 0.25 & -0.102 \\
\hline cg03419014 & chr21 & Island & HLCS & TSS1500 & $1.21 \mathrm{E}-03$ & 0.58 & 0.45 & 0.121 \\
\hline cg03543861 & chr21 & Island & & & $1.83 \mathrm{E}-02$ & 0.71 & 0.56 & 0.153 \\
\hline cg10384919 & chr22 & Island & MEl1 & TSS200 & $9.94 \mathrm{E}-03$ & 0.14 & 0.28 & -0.137 \\
\hline
\end{tabular}


bioRxiv preprint doi: https://doi.org/10.1101/2020.07.15.203075; this version posted July 15, 2020. The copyright holder for this preprint (which was not certified by peer review) is the author/funder, who has granted bioRxiv a license to display the preprint in perpetuity. It is made available under aCC-BY-ND 4.0 International license.

Table 2. Differentially methylated sites within the DSCR in myocardial DNA from subjects with DS.

\begin{tabular}{|c|c|c|c|c|c|c|c|c|c|}
\hline ID & position & strand & Relation to Island & $\begin{array}{l}\text { UCSC Reference } \\
\text { Gene Name }\end{array}$ & $\begin{array}{l}\text { UCSC Reference } \\
\text { Gene Group }\end{array}$ & adj P-Value & $\begin{array}{l}\beta \text {-value } \\
\text { NDS }\end{array}$ & $\begin{array}{l}\beta \text {-value } \\
\text { DS }\end{array}$ & $\Delta \beta$-value \\
\hline cg00994804 & 36259383 & - & Island & RUNX1 & 1stExon; Body & 0.006 & 0.123 & 0.318 & 0.196 \\
\hline $\operatorname{cg} 05409047$ & 37259564 & - & Island & & & 0.009 & 0.801 & 0.750 & -0.051 \\
\hline $\operatorname{cg} 13753900$ & 37528677 & + & Island & & & 0.042 & 0.137 & 0.086 & -0.050 \\
\hline $\operatorname{cg} 23933759$ & 37836671 & - & OpenSea & CLDN14 & 5'UTR & 0.039 & 0.753 & 0.693 & -0.060 \\
\hline $\operatorname{cg} 03419014$ & 38362742 & + & Island & HLCS & TSS1500 & 0.001 & 0.576 & 0.455 & -0.121 \\
\hline $\operatorname{cg} 16435782$ & 39087399 & - & OpenSea & KCNJ6 & Body & 0.030 & 0.805 & 0.771 & -0.034 \\
\hline $\operatorname{cg} 18539325$ & 39493489 & - & OpenSea & DSCR8; DSCR4 & TSS200 & 0.044 & 0.741 & 0.797 & 0.056 \\
\hline $\operatorname{cg} 21649569$ & 40752157 & - & Island & WRB & TSS200 & 0.010 & 0.150 & 0.115 & -0.035 \\
\hline
\end{tabular}


Table 3. Differentially methylated regions in myocardial DNA from subjects with DS.

\begin{tabular}{|c|c|c|c|c|c|c|c|}
\hline DMR & Chromosome & Start & End & Width & CpGs\# & $\begin{array}{l}\text { Min smoothed } \\
\text { FDR }\end{array}$ & Overlapping genes \\
\hline 1 & chr06 & 33282313 & 33283849 & 1537 & 37 & $5.24 \mathrm{E}-87$ & SNORA38, ZBTB22, SNORA20 \\
\hline 2 & chr06 & 31938527 & 31939884 & 1358 & 32 & $7.08 \mathrm{E}-99$ & SNORA38, STK19, DXO, SNORA20 \\
\hline 3 & chr06 & 30038754 & 30039380 & 627 & 27 & $1.33 \mathrm{E}-32$ & RNF39, SNORA20 \\
\hline 4 & chr06 & 28829171 & 28829503 & 333 & 13 & $8.22 \mathrm{E}-33$ & $\begin{array}{l}\text { RPL13P, XXbac-BPG308K3.6, } \\
\text { SNORA20 }\end{array}$ \\
\hline 5 & chr08 & 144808965 & 144810854 & 1890 & 7 & $5.80 \mathrm{E}-203$ & FAM83H \\
\hline 6 & chr08 & 144790187 & 144790410 & 224 & 5 & $5.70 \mathrm{E}-32$ & ZNF707, CCDC166 \\
\hline 7 & chr13 & 23309774 & 23310464 & 691 & 7 & $1.04 \mathrm{E}-35$ & SNORA16, SNORD37 \\
\hline 8 & $\operatorname{chr} 15$ & 91473059 & 91473569 & 511 & 9 & $2.78 \mathrm{E}-51$ & UNC45A \\
\hline 9 & chr16 & 2029256 & 2030009 & 754 & 4 & $4.15 \mathrm{E}-59$ & TBL3, NOXO1 \\
\hline 10 & $\operatorname{chr} 17$ & 20799408 & 20799644 & 237 & 6 & $4.83 \mathrm{E}-43$ & $\begin{array}{l}\text { SNORA69, RP11-344E13.3, } \\
\text { CCDC144NL }\end{array}$ \\
\hline 11 & chr18 & 77905119 & 77905947 & 829 & 10 & $2.57 \mathrm{E}-35$ & ADNP2, AC139100.2 \\
\hline 12 & chr19 & 55549414 & 55549842 & 429 & 8 & $4.79 \mathrm{E}-35$ & $\begin{array}{l}\text { CTC-550B14.7, GP6, CTC- } \\
\text { 550B14.6 }\end{array}$ \\
\hline 13 & $\operatorname{chr} 19$ & 2251588 & 2252029 & 442 & 4 & $1.53 \mathrm{E}-35$ & $\mathrm{AMH}$ \\
\hline 14 & chr22 & 45809244 & 45809793 & 550 & 14 & $4.71 \mathrm{E}-43$ & RIBC2, SMC1B \\
\hline 15 & chr22 & 42095347 & 42095536 & 190 & 6 & $5.52 \mathrm{E}-32$ & MEl1 \\
\hline 16 & chr22 & 51016703 & 51016950 & 248 & 3 & $1.64 \mathrm{E}-30$ & CPT1B, CHKB-CPT1B \\
\hline
\end{tabular}


bioRxiv preprint doi: https://doi.org/10.1101/2020.07.15.203075; this version posted July 15,2020 . The copyright holder for this preprint (which was not certified by peer review) is the author/funder, who has granted bioRxiv a license to display the preprint in perpetuity. It is made available under aCC-BY-ND 4.0 International license.

Table 4. Genes showing overlap with DMR in myocardial DNA from subjects with DS. Functional classification according to the PANTHER classification system.

\begin{tabular}{ll} 
Gene ID & Gene name \\
\hline AC139100 & Partitioning defective 6 homolog gamma \\
\hline ADNP2 & $\begin{array}{l}\text { Activity-dependent neuroprotector homeobox } \\
\text { protein 2 }\end{array}$ \\
\hline
\end{tabular}

$\begin{array}{ll}\text { AMH } & \text { Muellerian-inhibiting factor } \\ & \\ & \\ \text { CCDC144NL } & \begin{array}{l}\text { Putative coiled-coil domain-containing protein 144 } \\ \text { N-terminal-like }\end{array} \\ \text { CCDC166 } & \begin{array}{l}\text { Coiled-coil domain-containing protein 166 } \\ \text { CHKB-CPT1B readthrough (NMD candidate) } \\ \text { CHKB-CPT1B }\end{array} \\ \text { (Fragment) } & \text { Carnitine O-palmitoyltransferase 1, muscle isoform } \\ \text { DXO } & \text { Decapping and exoribonuclease protein }\end{array}$

$\begin{array}{ll}\text { FAM83H } & \text { Protein FAM83H } \\ \text { GP6 } & \text { Platelet glycoprotein VI } \\ \text { MEI1 } & \text { Meiosis inhibitor protein 1 } \\ \text { NOX01 } & \text { NADPH oxidase organizer 1 }\end{array}$

\begin{tabular}{|ll}
\hline RIBC2 & RIB43A-like with coiled-coils protein 2 \\
\hline RNF39 & RING finger protein 39 \\
\hline SMC1B & Structural maintenance of chromosomes protein 1B \\
\hline STK19 & Serine/threonine-protein kinase 19 \\
\hline
\end{tabular}

\begin{tabular}{lll}
\hline TBL3 & Transducin beta-like protein 3 & $\begin{array}{l}\text { maturation of SSU-rRNA from ticistronic rRNA transcript (SSU-rRNA, } \\
\text { 5.8S rRNA, LSU-rRNA; rRNA processing } \\
\text { muscle organ development; cell differentiation; chaperone-mediated } \\
\text { protein folding }\end{array}$ \\
\hline UNC45A & Protein unc-45 homolog A & $\begin{array}{l}\text { regulation of transcription by RNA polymerase II } \\
\text { regulation of transcription, DNA-templated }\end{array}$ \\
\hline ZBTB22 & Zinc finger and BTB domain-containing protein 22 & \\
\hline ZNF707 & Zinc finger protein 707 & \\
CTC-550B14.6 & Unable to map & \\
CTC-550B14.7 & Unable to map & \\
RP11-344E13.3 & Unable to map & \\
RPL13P & Unable to map & \\
SNORA16 & Unable to map & \\
SNORA20 & Unable to map & \\
SNORA38 & Unable to map & \\
SNORA69 & Unable to map & \\
SNORD37 & Unable to map &
\end{tabular}

\section{GO database Biological Process Complete}

centrosome cycle; establishment or maintenance of cell polarity; cell division; regulation of cellular localization; bicellular tightjunction assembly

regulation of transcription by RNA polymerase II; neuron differentiation; positive regulation of cell growth; cellular response to oxidative stress; negative regulation of cell death; cellular response to retinoic acid

preantral ovarian follicle growth; urogenital system development; Mullerian duct regression; cell-cell signaling; gonadal mesoderm development; sex determination; sex differentiation; aging; positive regulation of gene expression; response to organic cyclic compound BMP signaling pathway; response to drug; positive regulation of NFkappaB transcription factor activity; negative regulation of ovarian follicle development

phosphorylation; glycerophospholipid biosynthetic process

fatty acid metabolic process; fatty acid beta-oxidation; carnitine shuttle; carnitine metabolic process; long-chain fatty acid transport mRNA catabolic process; RNA destabilization; nuclear mRNA surveillance; nucleic acid phosphodiester bond hydrolysis; NAD-cap decapping

positive regulation of cell migration; biomineral tissue development; protein localization to cytoskeleton; intermediate filament cytoskeleton organization

enzyme linked receptor protein signaling pathway; blood coagulation; platelet activation; leukocyte migration

meiosis I; male meiosis I; spermatid development; meiotic telomere clustering

superoxide metabolic process; regulation of hydrogen peroxide metabolic process; extracellular matrix disassembly; positive regulation of catalytic activity; regulation of respiratory burst

\section{biological_process}

sister chromatid cohesion; meiotic cell cycle

protein phosphorylation; phosphorylation; positive regulation of Ras protein signal transduction muscle organ development; cell differentiation; chaperone-mediated protein folding regulation of transcription by RNA polymerase 